\title{
Talent Identification in Girls Soccer: A Process- Oriented Approach Using Small-Sided Games
}

\author{
Heinz Reinders ${ }^{1 *}$, Olaf Hoos ${ }^{2}$, Stefanie Varlemann ${ }^{1}$ and Sophie Howard ${ }^{3}$ \\ ${ }^{1}$ University of Wuerzburg, National Centre of Girls Soccer, Campus Hubland, Germany \\ ${ }^{2}$ University of Wuerzburg, Center for Research in Sports, Campus Hubland, Germany \\ ${ }^{3}$ TSG 1899 Hoffenheim, Center for Girls' and Women's Soccer, Germany
}

Submission: January 27, 2018; Published: February 15, 2018

*Corresponding author: Heinz Reinders, University of Wuerzburg, National Centre of Girls Soccer, Campus Hubland, Germany, Tel: (+49)9313185563; Email: heinz.reinders@nfz-juniorinnen.de

\begin{abstract}
This paper presents the development of a process-oriented assessment for adolescent elite soccer girls. Based on a $4 \mathrm{v} 4$ small-sided game (SSG) the test addresses seven dimensions of soccer skills which include technical and cognitive aspects of modern soccer play. A total of $\mathrm{N}=$ 195 female soccer players (mean \pm SD; age, 15, $11 \pm 0$, 88) participated in a test series whereby they completed the 4v4-SSG and a variety of motoric and cognitive tests. Results indicate that the newly developed SCORE test is a reliable and valid assessment for soccer skills and may help to identify talented players for researches and soccer coaches.
\end{abstract}

Keywords: Soccer; Talent diagnostics; Small-sided games

Abbreviations: SSG: Small-Sided Game; TID: Talent Identification and Development; SCORE: Soccer Competencies in Realistic Environments; IPS: Information Processing Speed

\section{Introduction}

Research on talent identification and development (TID) has increased over the past two decades. Three major tendencies have occurred within this field of research. Firstly, empirical data has been extended by theoretical developments to curtail "needle in the haystack"-research and to organize the mass of empirical results in a systematic model of TID [1]. Secondly, the focus on physiological preconditions has been complemented by studies on psychological measures of talented athletes [2]. Finally, research on talent identification strives particularly for more process- than product-oriented diagnostics. The latter is a major shift in talent identification research and practice. Nowadays it is not only measured how long it took an athlete to complete a task but the procedures with which a sports challenge is solved are also closely examined. This shift reflects the general development of research on athletes' expertise and competence [3]. The aim of the current study is to present a process-oriented assessment of adolescent girls' soccer skills. Using small-sided-games (SSG) and observing the performance of talented soccer girls during the SSG might give a better insight into their repeatedly occurring and hence stable competencies rather than merely testing their shooting or juggling skills in artificial settings.
These tests in soccer are known to be less reliable in identifying talents than assessing their performance in real game situations $[4,5]$. Moreover, the reliable and valid talent identification becomes more important for sports where the number of active athletes declines drastically. In Germany, for example, the number of girls' soccer teams has declined dramatically over the last few years. More than a quarter of active teams were withdrawn between 2010 and 2017 [6]. Due to the smaller population of female participants, the identification of talented athletes has to be more precise and should focus on the performance in simulated settings with challenges similar to those in real game situations. Small-sided games, where players perform their sport within a smaller spatial setting and with a reduced number of players, are becoming more relevant when assessing competence and selecting athletes for further talent promotion [7]. Recent research suggests that SSGs are reliable and valid indicators of physical strains, tactical behavior, and motoric competencies in young, elite soccer players [8].

Most assessments, however, are for academic purposes only and too complex to be of use to soccer coaches in their daily practice of identifying gifted players. The SSG-assessment 
presented here aims to fulfill both purposes: to render scientific test criteria and to meet the needs of soccer coaches in assessing talent in an appropriate manner. We therefore developed an observation tool with seven criteria for soccer skills which can be easily applied in soccer training and diagnostics. Furthermore, we tested its reliability and validity with a sample of 195 elite female soccer players aged 14- to 16-years. The results indicate that the chosen form of SSG-assessment map the tactical capabilities, technical skills and cognitive processes of decision-making that are considered essential requirements for elite soccer players.

\section{Methods}

\section{Participants and Study Design}

A total of 195 elite soccer girls were assessed with the newly developed "Soccer Competencies in Realistic Environments (SCORE)"-test in spring and summer 2017 (Mean \pm SD; age, $15,11 \pm 0$, 88). These players were recruited from ten German U17-Premiere League clubs (Bundesliga) and competence centers for talented soccer girls all over the country. The participants' parents gave their written permission to conduct tests with their daughters. These tests comprised (in order of application during the testing) a t-test of agility, a $20 \mathrm{~m}$-sprint, the SCORE-test, a cognitive test of information processing speed and a questionnaire containing several measures of training experience, motivation and goal orientation. This is therefore the largest and most comprehensive study in elite girls' soccer so far. A strict adherence to the sequence of tests was maintained at each club and competence center. The tests were conducted by intensively trained examiners to ensure comparability of data between subsamples. The testing procedures required a total testing time of 120 minutes for each athlete. All tests were run during the players' allocated training times.

\section{Assessing the "Soccer Competencies in Realistic Environments"-test (SCORE)}

The SSGs were played outdoors on a natural turf at the clubs' and competence centers' training facilities. The SSGs comprised a 4v4-teamplay without goalkeepers but with two small goals $(2 \mathrm{~m} \times 1 \mathrm{~m})$. The small goals were chosen to reduce the probability of long distance shots which might lead to fewer actions per player during the $2 \times 5$ minutes playtime (with a 1-minute break). The players were randomly assigned to one of the two teams and wore training shirts in two different colors, each team member being numbered from 1 to 4 for better identification during the observation and rating process. The field measured $30 \times 40$ meters with a total of 18 soccer balls surrounding the field (Figure 1). This was to reduce interruptions due to a lack of soccer balls and the girls were instructed to take the next available ball rather than retrieving the lost balls. The rules of the game were according to FIFA-norms for regular soccer games, with the exception that out-balls were brought back into play by kicking rather than throwing them in.

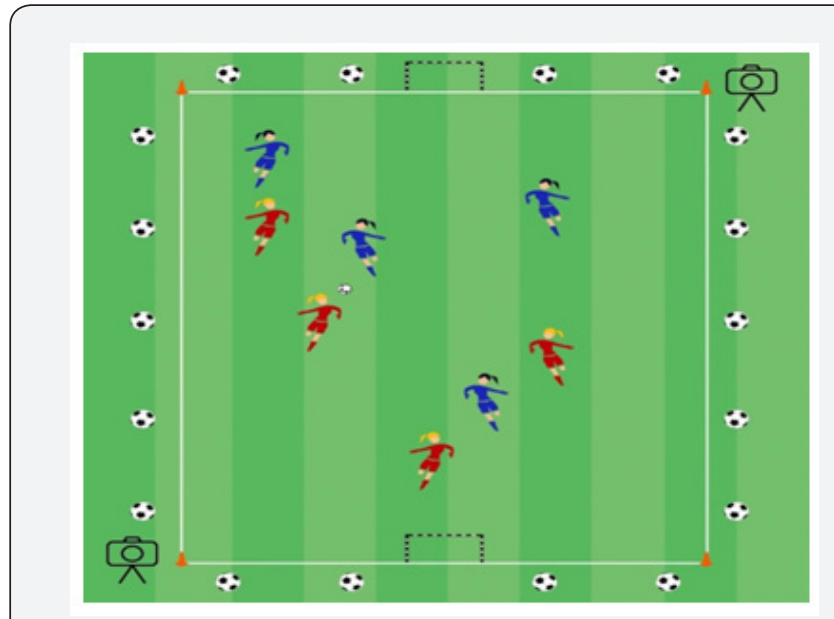

Figure 1: SCORE setting as a $4 \mathrm{v} 4$ small-sided game with camera and extra balls position.

A trained referee oversaw the game and interfered only if absolutely necessary. Each game was recorded with two HDvideo cameras (model "VTIN Eypro Full HD 1080p Action Cam”), positioned diagonally at two corners of the field to cover every inch of the pitch. The video material was stored and analyzed by four independent assessors, all four being experienced soccer players and girls' soccer coaches at the National Centre of Girls Soccer. The SCORE-test consists of seven dimensions. These were deduced from common concepts in elite soccer training. E.g., the famous elite youth player training of the Dutch soccer club Ajax Amsterdam, which led to the training concept of the unimaginably successful Spanish Club FC Barcelona, mainly consisting of the two core components technique and intelligence. English Premier League Clubs such as Manchester United or Arsenal London base their talent development programs on the training of technical skills and tactical understanding [9]. In addition, these training goals align with those of the German Soccer Association (DFB) which mainly address cognitive skills of game understanding and playing techniques [10].

Hence, these two major training goals were divided into seven subskills. One of them belongs to technical skills (receiving, controlling and passing the ball), three to the aspect of soccer understanding (game overview with and without ballpossession and creativity of actions) and the final three aspects concern skill performance as well as game understanding (offensive 1v1, defensive $1 \mathrm{v} 1$ and passing skills).

\section{a) Technical skills}

Receiving, controlling and passing the ball (recbal). This dimension measures the ability to control a received ball in a way which allows follow-up actions without time-loss (e.g. controlling a received ball with the left foot, immediate shift of the ball to the right foot and passing the ball without delay to a receiving player.

b) Soccer understanding 
Game overview without ball possession (over ball). Players with a good game overview without ball possession identify paths into free space, facilitating the receipt of a pass if ones' team is on the offensive. If the own team is on the defensive, players with good game overview move to areas of the field to narrow passing options for the rival team or to be more likely to intercept an opponent's pass.

Game overview with ball possession (over no ball). This competence includes the ability to take paths with the ball into free spaces, locate takers of the own team and avoid rival players. Furthermore, this dimension contains the appropriate decision of whether to risk a 1v1-situation, seek a shot on goal or to pass the ball to a teammate.

Creativity (creative). The player takes risks in her decision making due to her expectation of a major advantage for her own team. She overcomes typical soccer routines and shows unexpected solutions for a game situation.

c) Soccer understanding \& technical skills combined

Offensive 1v1 (o1v1). The player is able to keep the ball in a skilled manner even under the opponent's pressure and makes the right decisions to overcome the rival player without losing the ball.

Defensive 1v1 (d1v1). This dimension contains the ability to win the ball from the opponent, or to force her to slow down or seek less advantageous dribbling paths.

Passing skills (pass). Rather than addressing ball control skills only, this dimension also includes the ability to pass a ball to a teammate at the right moment, with the right speed and in the right direction in order to maintain ball possession and create advantageous tactical situations for the own team.

All seven dimensions were rated on a six-point Likertscale ranging from 1 (No performance) to 6 (Outstanding performance). Each level contains a description of the quantity as well as the quality of the performance shown by the players.

1) No performance: A player shows no performance of the dimension in question.

2) Very weak performance: A player shows a performance very rarely with no systematic reappearance and no successful task completion.

3) Weak performance: A player shows a performance occasionally with systematic reappearance and rare successful task completion.

4) Strong performance: A player shows a performance repeatedly with systematic reappearance and more successful than unsuccessful task completion.

5) Very strong performance: A player shows a performance repeatedly with systematic reappearance, some variations and mostly successful task completion.
6) Outstanding performance: A player shows a performance repeatedly with systematic reappearance, multiple variations and consistent successful task completion. Each dimension was rated by two observers for each player. The mean score of both observers was linked to the individual player's profile.

\section{Control Variables}

For validation of the SCORE assessment a 20-meter-sprint speed test, a t-test of agility, a test of information processing and questions about the duration of soccer experience were applied to the participants.

The 20-meter-sprint was measured in seconds by activating light barriers at the beginning and end of the 20 -meter distance. Players started this speed test in an upright position. The average speed of the players tested was $4.15 \pm 0.19$ seconds $(M \pm S D)$.

Agility was measured with a modified t-test of agility, where players started the t-test with either a red (go right) or green (go left) light signal to determine their sequence of running, sidesteps and backwards running. Time was taken in seconds and measured with a light barrier activated at the beginning and end of the movement sequence. Due to this modification with light signals this t-test contains a motoric (speed) and a cognitive component (reaction time to light signal). The participants achieved an average speed of $7.48 \pm 0.75$ seconds $(M \pm S D)$.

Information processing speed (IPS) was measured with the "Linking-Numbers-Speed-Test" [11] where players had three sheets with numbers ranging from 1 to 100 . The task was to link the numbers in the right order with a time limit of 60 seconds per sheet. The average of the highest number reached per sheet measures the average amount of bits per second processed by the players. The raw results are then transformed into distributions accounting for age and gender of the participants. The mean IQ for the players measured by the test was $118.22 \pm 13.71(\mathrm{M} \pm$ SD).

Soccer experience was asked in the questionnaire and the players could fill in the number of years they had already practiced soccer in a soccer club. The players of this study showed an average of $8.51 \pm 2.41(\mathrm{M} \pm \mathrm{SD}$ ) years of training in soccer clubs.

Age effects, relative age effects and Body-Mass-Index were taken into consideration but proven to be of no significance. Therefore, these variables were excluded from further analyses.

\section{Reliability of the SCORE test}

Cohen's kappa for Intercoder-Reliability of the four raters was $\kappa=0,702$ for 116 observed players with 812 observed game sequences. Results for internal consistency according to Cronbach suggest that all measured dimensions form the latent variable of overall soccer skills. Cronbach's alpha is $\alpha=0.87$ and item total correlations with $0.47<\mathrm{r}_{\mathrm{it}}<0.72$ stay within the acceptable range for the discrimination between items (Table 
1) [12]. Average scores for the dimensions show that creativity is the competence least presented $(\mathrm{M}=1.63)$ and skills of ball control (4.05), overview $(\mathrm{M}=3.92 / 3.96)$ and passing $(\mathrm{M}=$
3.95) are observed most often. Variations between players are comparable across all dimensions with creativity displaying a broader range of inter-individual difference.

Table 1: Means, standard deviations and internal consistency of the SCORE dimensions.

\begin{tabular}{|c|c|c|c|c|}
\hline & Mean & SD & $\begin{array}{l}\text { Corrected item total } \\
\text { correlation }\end{array}$ & $\begin{array}{c}\text { Cronbach's alpha, if item } \\
\text { deleted }\end{array}$ \\
\hline Recball & 4.05 & 0.88 & .717 & .813 \\
\hline Overball & 3.96 & 0.72 & .609 & .831 \\
\hline Overnoball & 3.92 & 0.84 & .724 & .813 \\
\hline Creative & 1.63 & 1.14 & .472 & .859 \\
\hline o1v1 & 3.37 & 0.93 & .541 & .839 \\
\hline $\mathrm{d} 1 \mathrm{v} 1$ & 3.56 & 0.89 & .601 & .830 \\
\hline Pass & 3.95 & 0.82 & .699 & .817 \\
\hline SCORE & 3.50 & 0.65 & & \\
\hline
\end{tabular}

\section{Validity of the SCORE test}

Table 2: Eigen values and explained variance of factor extraction.

\begin{tabular}{|c|c|c|c|}
\hline Factor & \multicolumn{3}{|c|}{ Eigen values } \\
\hline & Total & \% of variance & Cumulative \% of Variance \\
\hline 1 & 3.844 & 54.914 & 54.914 \\
\hline 2 & .790 & 11.292 & 66.207 \\
\hline 4 & .678 & 9.681 & 75.888 \\
\hline 5 & .494 & 7.057 & 82.945 \\
\hline 6 & .448 & 6.401 & 89.345 \\
\hline 7 & .405 & 5.785 & 95.130 \\
\hline
\end{tabular}

Exploratory factor analysis (principal component method with varimax rotation) shows that only the one-factor-solution meets the Kaiser-criterion for an eigenvalue $\lambda>1$ and the screeplot test illustrates the eigenvalue's disproportional increase from the one- to the two-factor solution [13]. The first factor has an eigen value $\lambda=3.84$, explaining 54.91 percent of the items' variance (Table 2). Hence, confirmatory factor analyses for comparing different factor-models show a significant decrease in fit statistics, i.e. Comparative Fit Index dropping from CFI = 0.96 for the one-factor solution to $\mathrm{CFI}=0.9^{\wedge}$ for the two-factormodel. Factor loadings show that each item loads on this one factor with a > .68 (Table 3).

Criterion validity was tested using bivariate correlations of the SCORE results with the 20-meter-sprint- and agility-test results as well as the number of years of training experience and the information processing speed (Table 4).

Table 3: Factor loadings for each item on the first factor.

\begin{tabular}{|c|c|}
\hline \multirow{2}{*}{} & Factor \\
\cline { 2 - 2 } & 1 \\
\hline recball & .736 \\
\hline overball & .822 \\
\hline overnoball & .806 \\
\hline creative & .824 \\
\hline o1v1 & .656 \\
\hline d1v1 & .726 \\
\hline pass & .583 \\
\hline
\end{tabular}

Table 4: Bivariate correlations (Pearsons $r$ ) of the SCORE results with selected motoric and cognitive measures.

\begin{tabular}{|c|c|c|c|c|}
\hline \hline & 20m-sprint & Agility & IPS & Training Experience \\
\hline SCORE & $-0.19^{* *}$ & $-0.32^{* * *}$ & $0.20^{* *}$ & $0.17^{*}$ \\
\hline
\end{tabular}

${ }^{* * *} p<0.001 ;{ }^{* *} p<0.01 ;{ }^{*} p<0.05$ “

The results indicate that the soccer performance measured by the SCORE test is moderately but significantly linked to the players' motoric ( $\mathrm{r}=-0.19$ for the $20 \mathrm{~m}$-sprint) and cognitive characteristics ( $r=0.20$ for the information processing speed) as well as their soccer experience $(r=0.17)$. The strongest connection was found for the SCORE results and the players' agility $(r=-0.32)$. This fits into theoretical considerations, assuming that the SCORE test measures technical and intellectual aspects of modern soccer. Further correlation analyses on the level of single items differentiate the overall correlation between SCORE and the control variables (Table 5). It is remarkable that the motoric variable of sprint speed is significantly linked 
to the technical skill of ball receiving $(r=-0.17)$ and the two $1 \mathrm{v} 1$-variables $(\mathrm{r}=-0.25 /-0.20)$ while the cognitive measure of information processing speed is only significantly correlated with the aspects of soccer understanding $(-0.19<<\mathrm{r}<-0.27)$.
The t-test of agility, which contains a motoric and an intellectual component is correlated with almost all dimensions of the SCORE test $(-0.22<\mathrm{r}<-0.36)$.

Table 5: Bivariate correlations (Pearsons $r$ ) of the SCORE dimensions with selected motoric and cognitive measures.

\begin{tabular}{|c|c|c|c|c|}
\hline & 20m-sprint & Agility & IPS & Training Experience \\
\hline \multicolumn{5}{|c|}{ Technical Skills } \\
\hline Recball & $-0.17^{*}$ & -0.10 & 0.08 & $0.25^{* *}$ \\
\hline \multicolumn{5}{|c|}{ Soccer Understanding } \\
\hline Overball & -0.15 & $-0.36^{* * *}$ & $-0.27^{* * *}$ & 0.12 \\
\hline overnoball & -0.09 & $-0.30 * * *$ & $-0.19^{* *}$ & 0.09 \\
\hline creative & -0.08 & $-0.29 * * *$ & $-0.23^{* *}$ & 0.02 \\
\hline \multicolumn{5}{|c|}{ Technical Skills and Soccer Understanding } \\
\hline o1v1 & $-0.25^{* *}$ & $-0.27^{* * *}$ & $-0.16+$ & 0.11 \\
\hline $\mathrm{d} 1 \mathrm{v} 1$ & $-0.20^{* *}$ & $-0.22^{* *}$ & -0.11 & 0.12 \\
\hline pass & -0.07 & $-0.15^{*}$ & $-0.18^{*}$ & $0.19 *$ \\
\hline
\end{tabular}

*** $\mathrm{p}<0.001 ;{ }^{* *} \mathrm{p}<0.01{ }^{*} \mathrm{p}<0.05$

Nevertheless, closest relations can be indicated between the t-test and those measures of SCORE, which address soccer understanding $(-0.29<\mathrm{r}<-0.36)$. These selective correlation patterns strongly suggest, that the (mainly) technical skills measured by SCORE are more related to motoric preconditions whereas measures of cognitive skills of soccer understanding within SCORE are closer to the players' intellectual skills of information processing speed. Finally, training experience obviously only leads to improvements in ball receiving $(r=0.25)$ and passing skills $(r=0.19)$. This goes along with the critics about German training concepts which mostly address technical rather than intellectual skills [6]. Therefore, the SCORE test is thought to be of sufficient criterion validity.

\section{Discussion}

This contribution presents a newly developed test for assessing adolescent players' soccer skills. The "Soccer Competencies in Realistic Environments"-test (SCORE) is based on simulating real game situations through small-sided games where a reduced number of players compete on a smaller pitch are observed regarding their soccer ability [14]. The aim of SCORE is to provide a reliable and valid tool for scientific and practical purposes which researchers and coaches can use to identify players' soccer performance and specific performance profiles. Its process-oriented approach allows for a much more precise identification of talented players since data on both technical and intellectual skill is gathered during the performance in vivo. This approach surpasses the limitations of assessments in artificial situations with artificial tasks and therefore avoids "teaching-to-test" - effects [15]. E.g. juggling a ball or completing a standardized - dribbling parkour is a result of stereotype training with unchanged motoric and intellectual challenges. Solving permanently changing game situations with numerous variables to be considered at each moment needs constant development of motoric competencies and cognitions.
SCORE takes the competences needed for modern soccer into account and enables coaches to rate their players' skills by means of the SCORE scheme. The coaches derive a reliable and valid profile for each player, receiving information about each player's relative position within the team as well as the individual's specific strengths and weaknesses. SCORE therefore provides information about which skills require further development for the whole team and individual players. Limitations of SCORE emanate from the sample, consisting of soccer girls aged 14 to 16 years. Therefore, it is necessary to extend its range to younger players as well as to adult soccer players in higher leagues in order to assert its reliability and validity for those populations and to develop normal distributions of soccer skills for different age groups. Also, the application of SCORE to male soccer players and comparisons of skill profiles by gender are the next important steps to increase the test's application possibilities in talent identification and development [16].

\section{Acknowledgement}

This study was made possible due to the support of the German elite clubs (in alphabetical order) FFV Heidenheim, TSG 1899 Hoffenheim, Bayer 04 Leverkusen, 1 FC Nürnberg, VFL Sindelfingen and the elite soccer camps of the soccer associations of Berlin, Hesse, Lower-Saxony and North-Rhine Westphalia. We would also like to thank the diagnostics team Sarah Dorsch, Sebastian Grunert, Astrid Kötterl, Ulrike Kutschera, Steve Vaughan, Lysanne Väth, and Mareen Wiechers.

\section{References}

1. Bailey R, Morley D (2006) Towards a model of talent development in physical education. Sport, Education and Society 11(3): 211-230.

2. Lawrence I (2010) Talent identification in soccer: A critical analysis of contemporary psychological research. Soccer Journal 53(4): 24-26.

3. Araújo D, Fonseca C, Davids K, Garganta J, Volossovitsch A, et al. (2010) The role of ecological constraints on expertise development. Talent Development \& Excellence 2(2): 165-179. 
4. Höner O, Votteler A, Schmid M, Schultz F, Roth K (2015) Psychometric properties of the motor diagnostics in the German football talent identification and development program. Journal of Sports Sciences 33(2): 145-159.

5. Garganta J, Santos R, Da Costa IT (2014) Comparison of tactical behavior and performance of youth soccer players in 3v3 and 5v5 small-sided games. International Journal of Performance Analysis in Sport 14(4): 801-813

6. Reinders H, Hoos O, Haubenthal G (2015) Bedingungen erfolgreicher Förderung von Mädchen im Breiten- und Leistungs football. (Conditions of effective talent development of soccer girls). National Institute for Girls Soccer, Julius Maximilians University of Wuerzburg, Germany.

7. Fenner JS, Iga J, Unnithan V (2016) The evaluation of small-sided games as a talent identification tool in highly trained prepubertal soccer players. Journal of Sports Sciences 34(20): 1983-1990.

8. Hill Haas SV, Dawson B, Impellizzeri FM, Coutts AJ (2011) Physiology of small-sided games training in football. Sports Medicine 41(3): 199220

9. Stratton G, Reilly T, Williams AM, Richardson D (2004) Youth soccer: From science to performance. Routledgen Company Publishers, New York.
10. Wein H (2011) Spielintelligenz im Fu $\beta$ ball - kindgemä $\beta$ trainieren. (Training children's intelligence in soccer). Meyer \& Meyer, Aachen, Germany.

11. Oswald WD (2016) Der Zahlen Verbindungs Test (ZVT). Göttingen: Hogrefe, Germany.

12. Cronbach LJ (1951) Coefficient alpha and the internal structure of tests. Psychometrika 16(3): 297-334

13. Ford JK, Mac Callum RC, Tait M (1986) The application of exploratory factor analysis in applied psychology: A critical review and analysis. Personnel Psychology 39(2): 291-314.

14. Sannicandro I, Cofano G (2017) Small-sided games in young soccer players: Physical and technical variables. MOJ Sports Medicine 1(1): $1-4$.

15. Baker J, Cobley S, Schorer J (2012) Talent identification and development in sport. International perspectives. Routledge Company Publishers, London.

16. Memmert D (2010) Testing of tactical performance in youth elite soccer. Journal of Sports Sciences and Medicine 9(3): 199-205.

\section{Your next submission with Juniper Publishers} will reach you the below assets

- Quality Editorial service

- Swift Peer Review

- Reprints availability

- E-prints Service

- Manuscript Podcast for convenient understanding

- Global attainment for your research

- Manuscript accessibility in different formats

( Pdf, E-pub, Full Text, Audio)

- Unceasing customer service

Track the below URL for one-step submission https://juniperpublishers.com/online-submission.php 